\title{
RCT of EPIDURAL MORPHINE FOR POST-VAGINAL PERINEAL PAIN
}

Authors: Dr. A. Macarthur MD, Dr. C. Imarengaiye MbCHB, Dr. L. Tureanu MD, Lynn Iheme $\mathrm{BScN}$, Kristi Downey MSc

Affiliation: Department of Anesthesia, Mount Sinai Hospital, 600 University Avenue, Toronto, Ontario, Canada M5G 1X5

Introduction: Epidural morphine usefulness in treating post-vaginal delivery perineal pain is unclear. Our study hypothesis was that a single dose of epidural morphine following a vaginal delivery would diminish acute postpartum perineal pain compared to placebo.

Methods: This randomised double-blind placebo-controlled trial was conducted at an academic obstetric unit after receiving institutional REB approval. Subjects were recruited from women who had chosen epidural analgesia for labor. Following vaginal delivery all consenting participants were randomized to either $2.5 \mathrm{mg}$ epidural morphine or $10 \mathrm{ml}$ saline. The randomization schedule was stratified by parity. All patients received a scheduled course of acetaminophen and NSAID for 24 hours. The primary outcome was the proportion of women in each group who requested extra analgesia in the first 24 hours postpartum, analysed by intention to treat. Secondary outcomes included: time to request for analgesia, maternal pain scores, maternal satisfaction, and incidence of pruritus, nausea / vomiting, drowsiness and urinary retention. Demographic information was collected on potential confounding variables.

Results: 231 women were randomized in the study: 3 were withdrawn following randomization and 228 women were appropriate for study. (155 primiparous: 73 multiparous patients). The two groups did not differ by potential confounders. Results of outcomes are presented in the table below. Survival analysis indicated the time to first request in the 24 hours postpartum was earlier for the placebo group (18 $9 \pm 8.03 \mathrm{hrs})$ compared to the morphine group $(22.9 \pm 4.04 \mathrm{hrs})$, $\mathrm{p}<0.000$.

Discussion: Women not receiving epidural morphine following a vaginal delivery were 4.5 times (95\% CI: $2.4,85$ ) more likely to require additional analgesics in the $1^{\text {st }} 24$ hours postpartum and require it earlier. The analgesic effect of epidural morphine was consistent for both primiparous and multiparous patients.

\begin{tabular}{|c|c|c|c|}
\hline Outcome & $\begin{array}{l}\text { Morphine group } \\
(\mathrm{N}=113)\end{array}$ & $\begin{array}{l}\text { Saline group } \\
(\mathrm{N}=115)\end{array}$ & $p$ value \\
\hline $\begin{array}{l}\text { \# women additional analgesic } \\
\text { postpartum }\end{array}$ & $\begin{array}{c}8 \\
(7 \%)\end{array}$ & $\begin{array}{c}37 \\
(32 \%)\end{array}$ & 0.000 \\
\hline $\begin{array}{l}\text { VAS @ time of extra analgesic } \\
\text { (sd) }\end{array}$ & $\begin{array}{c}4.6 \\
(2.6) \\
\end{array}$ & $\begin{array}{c}5.2 \\
(2.1) \\
\end{array}$ & 0.50 \\
\hline $\begin{array}{l}\text { Incidence of: } \\
\text { Pruritus } \\
\text { Nausea / Vomit } \\
\text { Urinary retention }\end{array}$ & $\begin{array}{l}13 / 108 \\
10 / 107 \\
20 / 109\end{array}$ & $\begin{array}{c}16 / 109 \\
5 / 109 \\
11 / 111\end{array}$ & $\begin{array}{c}0.099 \\
0.19 \\
0.08\end{array}$ \\
\hline
\end{tabular}

